\title{
Estrategias para trabajar el plan lector a partir de las inteligencias múltiples y la teoría de la comprensión
}

\section{"Saber para pensar con rigor, ser creativo y orientar la vida hacia el ideal de unidad y solidaridad»}

Lic. Elizabeth Galeano de Cardona.

Leer, debe estar asociado con comprensión y aprendemos más fácil lo que comprendemos, esto conlleva a desarrollar la capacidad de reflexión, a fomentar métodos y estrategias que se adapten a las necesidades de las estudiantes y a su contexto.

A partir de la experiencia los docentes del Colegio de Nuestra Señora del Rosario de Manizales, en el colectivo de Humanidades Lengua Castellana, han venido trabajando los últimos cuatro (4) años, el plan de lectura desde cuatro actividades que han dado grandes resultados evidenciados en las estudiantes de $4^{\circ}$ a $11^{\circ}$, que son con quienes se trabaja este proyecto, cada vez son más creativas para la presentación o exposición de los trabajos y de la misma manera se ha verificado la promoción de las diversas inteligencias múltiples y la teoría de la comprensión en este proyecto.

Al iniciar el año escolar en cada uno de los grupos se plantean cuatro actividades, una para cada período y la lectura de un libro de literatura por período: expresión oral, reseña, Parafernalia y álbum, luego se divide cada uno de los grupos en cuatro subgrupos con el fin de que a cada uno de ellos le toque una de estas actividades así, por ejemplo si el grupo es de 32 estudiantes como en el caso de los 7 mos; 8 estudiantes trabajarán expresión oral, 8 estudiantes reseñas, 8 estudiantes parafernalias y las últimas 8 álbum, pero cada uno de los siguientes períodos se harán cargo de las otras actividades.

Cada una de estas actividades es individual y para la expresión oral la estudiante debe traer a clase como material un collage o dibujo que muestre el texto por sí sólo, y exponer a partir de la macroestructura (descripción del contenido del texto en forma general); la superestructura (presenta- ción de la obra, distribución, género, época a la pertenece y temática que maneja); el argumento (a través del cual plantea minuciosamente la historia, se presentan los personajes, los conflictos que quiere dar a conocer el autor) y por último la estudiante plantea su posición personal frente al texto leído.

Para la segunda actividad, la estudiante lee el libro y entrega una reseña escrita a partir de los siguientes pasos:

- Nombre del libro, nombre del autor, editorial, número de páginas, género del libro etc.

- Contextualización y presentación del autor, se sitúa el texto en un conjunto más amplio de la literatura, se compara con otras obras del mismo autor o del mismo género o se involucra en un género literario.

- Presentación del texto y sus características, se expone de manera muy precisa el argumento, aspectos importantes y estilo del autor.

- Posición personal e interpretación de la obra reseñada, aquí se hace un juicio o interpretación del texto destacando aspectos positivos o negativos, se da la opinión personal y se busca contagiar al lector para que luego lea el libro.

En cuanto a la tercera actividad, la parafernalia, las estudiantes con anterioridad se encargan de organizar el escenario, todas las parafernalias se realizan al mismo tiempo en un aula máxima o salón grande pero con la técnica de la rejilla (rotando más o menos cada 10 minutos con el fin de alcanzar a socializarlas) ; para esta actividad la estudiante trae los objetos más importantes a los que haga referencia la obra y a partir de ellos hace la exposición dando a conocer la importancia de los mismos, los protagonistas de la obra, de igual manera trae una ayuda audio visual con la biografía del autor y un corto argumento de la obra, lo más importante de esta actividad además de la socialización que haga la estudiante, es la decoración o escenografía, la vestimenta que se use, la música alusiva a la obra o 
a la época y los otros textos del mismo autor que traiga la estudiante ese día para resaltar el grado de importancia de este escritor y de manera especial para motivar a sus compañeras a conocer la producción intelectual y artística de éste.

Para la última actividad, la estudiante debe hacer un gran uso de su creatividad y realizar un trabajo a manera de álbum donde todo el material preparado debe ir pegado (el argumento, las láminas alusivas a la obra, vida y obras del autor y posición personal).

La expresión oral y la parafernalia son actividades orales o expositivas, la reseña y el álbum son actividades escritas.

Cada una de estas actividades tiene importancia para el desarrollo de las múltiples inteligencias de las cuales habla Howard Gardner en el proyecto cero de la Universidad de Harvard y de manera especial en la inteligencia lingüística cuando la estudiante se expresa en forma oral, con un amplio vocabulario que hace más fácil la asimilación del texto por parte de sus compañeras; la inteligencia espacial y visual cuando imagina y plasma el collage con el cual va a representar su obra; inteligencia interpersonal e intrapersonal cuando se expresa frente a un auditorio argumentando y defendiendo la posición personal y los sentimientos frente a la obra leída; inclusive se reconoce también la inteligencia musical cuando es capaz de seleccionar la melodía adecuada para colocarle de fondo a la parafernalia y además tiene gusto y aceptación por éste tipo de música; todas estas inteligencias se manifiestan en las habilidades, los gustos o las potencialidades que se desarrollan en las estudiantes y se evidencian a lo largo del proceso de las clases.

En cuanto a la teoría de la comprensión, a partir de este tipo de actividades que se trabaja en el plan lector se identifican habilidades, conocimientos y competencias esenciales que se adquieren cuando las estudiantes van más allá de lo simple y se involucran más directamente con las obras y los autores profundizando, aprehendiendo y fomentan- do valores que el libro con el cual trabajan el proyecto lector trae inmerso.

A través de este trabajo las estudiantes aprenden a extractar de los textos los contenidos esenciales, a alcanzar conscientemente la comprensión, a desarrollar habilidades de pensamiento de alto nivel a través de las preguntas y reflexiones que se hace cada una de ellas o que hacen a sus docentes para clarificar diferentes aspectos de la obra; mediante la lectura y las actividades con las cuales preparan la exposición o los trabajos escritos.

Es muy importante para alcanzar la comprensión, darle participación a la estudiante mediante la selección adecuada del texto que va a leer, esto se logra con una socialización previa de las obras por parte del docente, dándoles a conocer diferentes tipos de textos y de autores de acuerdo al grupo, intereses, contexto social y cultural y aplicación que se le pueda dar al texto leído, para fomentar los valores o relacionando los contenidos con experiencias personales o aplicando los conocimientos a nuevas situaciones. También se trabaja la enseñanza para la comprensión cuando se conviene la forma en que se evaluarán los procesos de este proyecto, ya que de antemano la estudiante sabe que es lo más importante que ella debe seleccionar como conocimiento y hacer de lado los aspectos de poca importancia.

Para terminar, vale la pena anotar que las estudiantes del colegio de Nuestra Señora del Rosario de los grados séptimo y octavo del año 2003 realizan otra multiplicidad de actividades como exposiciones de temas libres, recitales poéticos, cuenteras y el trabajo final del proyecto lector el cual es un montaje que elaboran las estudiantes de séptimo con poetas caldenses y las de octavo tienen libertad para escoger el autor con el cual van a trabajar aunque en años anteriores se trabajaron poetas colombianos, este año la elección fue diferente debido a los estándares de calidad del área de castellano planteados por el M.E.N.

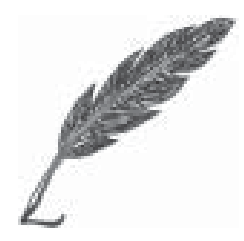

124 • FACULTAD DE FDUCACIÓN 